\title{
Andrzej Sieradzki
}

Uniwersytet im. Adama Mickiewicza w Poznaniu

\section{Słowotwórstwo nazwisk mieszkańców wsi we wrzesińskich księgach chrztu z XVIII wieku}

Opis identyfikacji osób w dokumentach historycznych może być dokonywany z dwóch perspektyw: szerszej, uwzględniającej całe notowane w tekstach frazy nominalne, referujące konkretne osoby [zob. np. Klisiewicz 1976; Mączyński 2002; Sieradzki, Sieradzka, Rudnicka-Fira 2004; Sieradzki 2011], lub węższej, uwzględniającej wyłącznie substancję antroponimiczną, czyli imię i nazwisko.

Wiek XVIII to okres w rozwoju nazwiska polskiego, w którym ciągle jeszcze identyfikacja osób należących do stanu chłopskiego przez dwuelementowy paradygmat nazewniczy, imię i nazwisko, nie jest powszechna. Tendencje wówczas panujące można odtworzyć na podstawie analizy występujących w dokumentach grup nominalnych o referencji osobowej, mających charakter deskrypcji jednostkowych. Na stopień upowszechnienia się nazwiska wskazuje relacja pomiędzy grupami opartymi na połączeniu imienia i nazwiska, np. Joannes Kulicki, braseator de villa Gutovo, oraz na samym imieniu, np. Josephus, ferrifaber, de Bierzglinko. Nieprzydatne do tego rodzaju ustaleń są same spisy nazwisk. Danych wynikających z tego rodzaju porównań nie można oczywiście absolutyzować, pokazują one jednak dowodnie tendencje nominacyjne panujące $\mathrm{w}$ danym dokumencie w odniesieniu do poszczególnych grup stanowych. Można bowiem założyć, że jeśli nazwisko nie pojawia się w dokumencie oficjalnym, to nie występowało ono też zazwyczaj w rzeczywistości. Jak wynika z prowadzonych przeze mnie wcześniej badań, liczba osób (rodziców chrzczonych dzieci) identyfikowanych przez imię i nazwisko w badanych dokumentach z lat 1700-1725 to zaledwie 20\% wszystkich zapisów. Pozostałe adnotacje to grupy oparte na samym imieniu z przydanymi dodatkowymi elementami identyfikującymi [Sieradzki 2011: 141]. Liczba grup opartych na dwóch członach antroponimicznych zwiększa się stopniowo 
do końca XVIII wieku. Jak wynika z pobieżnych obliczeń, prowadzonych na użytek niniejszego tekstu, nie przekracza jednak 60\%. Sytuację w pewnym stopniu może zniekształcać przyjęta w księgach w odniesieniu do ludności wiejskiej konwencja zapisu.

Stan widoczny w metrykach chrztu z Wrześni ${ }^{1}$ wyraźnie kontrastuje z tym, co w odniesieniu do ksiąg gromadzkich ze wsi Jadowniki pisze Maciej Mączyński [2002: 198-199]:

Identyfikacja stron (chłopów) w KGJ dokonywana jest przez imię i nazwisko. Wymienia się je na początku zapiski, zaraz po formule wstępnej [...].

I dalej:

O wiele częściej jednak w KGJ obok imienia i nazwiska (czasem samego imienia lub samego nazwiska) pojawia się deskrypcja określona [...].

W obu przypadkach sporządzający zapiski konstruują grupy o charakterze deskrypcji jednostkowych w sytuacji o parametrach hic et nunc. Inna jest jednak sytuacja komunikacyjna. Abstrahując od różnic związanych z charakterem obu zdarzeń (rozprawa sądowa, akt chrztu), stwierdzić trzeba, że podstawowa przyczyna, wpływająca na kształt poszczególnych deskrypcji, a dokładniej na budowę ich antropologicznej podstawy (imię/imię i nazwisko), związana jest bezpośrednio z punktem widzenia, z którego redagowany jest tekst. W przypadku ksiąg jadownickich jest to miejsce rozprawy. W związku z tym z repertuaru dostępnych środków identyfikacji odpadają frazy oparte na imieniu z przydaną informacją o miejscu pochodzenia danej osoby ${ }^{2}$, bowiem nie mają one wówczas mocy indywidualizującej i identyfikującej zarazem. Inaczej sytuacja wygląda w przypadku ksiąg wrzesińskich, w których osoby identyfikowane przez poszczególne frazy pochodzą z zewnątrz. W procesie identyfikacji możliwe było więc użycie fraz opartych na imieniu z dodatkowym elementem identyfikującym o charakterze lokatywnym, np. Johannes de Cho-

1 Księgi chrztu parafii farnej we Wrześni przechowywane są w Archiwum Archidiecezjalnym w Gnieźnie. Zawierają metryki chrztu sporządzane od 1700 roku. W tym artykule wykorzystuję wyłącznie te zapiski metrykalne, które informują o chrzcie dzieci chłopskich ze wsi należących do parafii farnej.

2 Zofia Kaleta [1991: 41-74], badając ewolucję nazwisk słowiańskich, zauważyła, że grupy nominalne o referencji osobowej (w sytuacji o parametrach hic et nunc, spełniające definicję deskrypcji określonej) były pierwszym sposobem, przed wykształceniem się syntetycznych form nazwiska, identyfikacji osobowej. 
cicza. Szerzej obydwie sytuacje analizuję w pracy o poznańskich derywatach nazwiskowych, tu zatem tylko sygnalizuję problem [Sieradzki 2013: 28-32].

Analiza badanych tekstów pokazuje, że jeszcze w 2. połowie XVIII wieku tylko ok. $60 \%$ osób identyfikowano przez imię i nazwisko. Pozostałe jednostki rozpoznawano przez grupy nominalne o charakterze deskrypcji określonej, opartej na imieniu z przydanymi determinatorami lokatywnymi oraz często też nazwą wykonywanego zajęcia (rataj, pasterz) czy statusu ekonomicznego (kmieć, pótrolnik, chatupnik). Tych dodatkowych determinatorów nie traktuję jako nazwisk. We wspomnianych już grupach nominalnych opartych na dwóch członach antroponimicznych poświadczonych zostało przez cały XVIII wiek 317 nazwisk, przy czym ponad połowa z nich (161) to nazwiska niemotywowane słowotwórczo. Derywaty nazwiskowe zamykają się zatem liczbą 156 jednostek. Za derywowane uznaję, zgodnie z założeniami przyjętymi w pracy o poznańskich derywatach nazwiskowych [Sieradzki 2013], wyłącznie te jednostki, które utworzone zostały formantami -ski (i pochodnymi) -ewicz, -owicz oraz z podstawowym - $k$-. W toku analiz słowotwórczych derywat ujmuję wyłącznie in statu nascendi, a nie jako jednostkę leksykonu. Stąd też, analogicznie jak w słowotwórstwie apelatywnym, za podstawowe uznaję zarówno nazwiska nierozbudowane słowotwórczo, np. Jaskóła, jak i te, które utworzono według produktywnych na gruncie nazwiskowym procesów słowotwórczych. Taka postawa badawcza rzutuje również na rozstrzygnięcia w zakresie sufiksu, który brał udział w procesie słowotwórczym, np. w derywatach typu Zawacki (<Zawady) wyodrębniam formant -ski a nie -cki. Podstawę wyodrębnienia poszczególnych modeli słowotwórczych stanowi formant, stąd też dla ogólnej charakterystyki systemu słowotwórczego istotna jest decyzja o wyborze takiej czy innej jego postaci. Szczegółowy rozkład poszczególnych sufiksów w nazwiskach derywowanych poświadczonych we wrzesińskich księgach chrztu przedstawia poniższa tabela:

Tabela 1. Rozkład sufiksów w nazwiskach derywowanych

\begin{tabular}{|l|r|r|}
\multicolumn{1}{|c|}{ Sufiks } & Liczba & Procent \\
\hline z podstawowym - $k$ - & 97 & 61,9 \\
\hline -ski (i warianty) & 52 & 33,5 \\
\hline -ewicz, -owicz & 7 & 4,6 \\
\hline Razem & $\mathbf{1 5 6}$ & $\mathbf{1 0 0 , 0}$ \\
\hline
\end{tabular}


Największą aktywność słowotwórczą, jak pokazuje zestawienie, przez cały badany okres wykazują formanty z podstawowym $-k$-. Te formanty Józef Bubak [1986] uznaje za dominujące w nazwisku chłopskim w ogóle. W badanym materiale stosunkowo dużo jest również derywatów z formantem -ski (we Wrześni jest on dominującym wykładnikiem derywacji). Przez pojedyncze przykłady poświadczone są formanty -ewicz, -owicz. Stan obserwowany na podwrzesińskiej wsi XVIII-wiecznej przypomina stan charakterystyczny dla XVI-wiecznych Szamotuł [Sieradzki (w druku)]. Szczegółową charakterystykę poszczególnych formantów występujących w badanych derywatach nazwiskowych przedstawiam poniżej.

\section{Derywaty z formantami: $-a k, e k,-i k,-k a,-k o,-c z y k$}

Wiek XVIII to okres, w którym omawiane formanty pełnią jeszcze podwójną funkcję. Z jednej strony są wykładnikami żywej, ciągle identyfikującej relacji patronimicznej (jako jedyne; formanty -ewicz, -owicz straciły tę funkcję już w połowie XVII wieku). Z drugiej strony występują w formalnych modelach słowotwórczych, według których tworzone są formy nowych nazwisk od nazwisk już istniejących (szerzej omówię to zjawisko niżej). Udział poszczególnych formantów w derywacji nazwiskowej jest nierównomierny. Dokładne dane prezentuje tabela 2 .

Tabela 2. Udział poszczególnych formantów $w$ derywacji nazwisk

\begin{tabular}{|l|c|r|}
\hline \multicolumn{1}{|c|}{ Sufiks } & Liczba & Procent \\
\hline$-a k$ & 49 & 50,5 \\
\hline$-e k$ & 21 & 21,6 \\
\hline$-i k$ & 9 & 9,3 \\
$-k a$ & 8 & 8,2 \\
\hline$-k o$ & 1 & 1,1 \\
\hline$-c z y k$ & 9 & 9,3 \\
\hline Razem & $\mathbf{9 7}$ & $\mathbf{1 0 0 , 0}$ \\
\hline
\end{tabular}

Największą aktywność derywacyjną w badanym okresie, jak wynika z tabeli, wykazuje sufiks -ak. Tworzy dwukrotnie więcej derywatów nazwiskowych niż następny w kolejności sufiks -ek. Brak niestety materiału porównawczego 
ze wsi wielkopolskiej, który pozwoliłby stwierdzić, czy było to zjawisko typowe dla szerszego obszaru, czy miało tylko charakter regionalny. Formant ten wymienia w artykule o XVII-wiecznych nazwiskach mieszczańskich i chłopskich z terenu Wielkopolski także Tadeusz Skulina [1989: 199]. Nie podaje jednak żadnych danych, które wskazywałyby na jego produktywność w porównaniu z innymi formantami. Diametralnie odmienną sytuację pokazuje materiał poznański. $\mathrm{W}$ badanym okresie derywaty $\mathrm{z}$ formantami $\mathrm{z}$ podstawowym - $k$ - miały już na tym obszarze charakter regresywny. Wypierane były przez typy z formantami -ski (i pochodnymi) oraz -ewicz, -owicz. Wewnątrz tej grupy dominowały natomiast dwa formanty: -ek oraz -ik [Sieradzki 2013]. W świetle dotychczasowych badań stan poświadczony na wsiach położonych wokół Wrześni jest wyjątkowy. Problem wymaga jednak dalszych poszukiwań, opartych na danych z tekstów, które powstawały na terenie parafii wiejskich.

Tak duża produktywność omawianego formantu (i w ogóle modeli słowotwórczych z podstawowym -k-) na badanym terenie mogła mieć dwie przyczyny: a) derywaty z omawianymi formantami były jedynymi, które wyrażały jeszcze relację patronimiczną, b) formant - $a k$ był popularnym wykładnikiem derywacji w formalnych modelach słowotwórczych. Pierwszy z wymienionych przypadków został w badanych tekstach poświadczony przez jedną frazę, w której expressis verbis zawarta została informacja o wspomnianej wyżej relacji semantycznej: Sebastianus Chojnaczczak filius L. Joannis ex eadem villa (1748), cf. Joannis et Reginae Chojnackich de Zawodzie (1728). Warto dodać, że w gwarach okolic Wrześni formant - ak wyrażał jeszcze w końcu XX wieku ogólnie pojęte pochodzenie z danej rodziny (relacja patronimiczna była już zatarta), np. Te Trawińszczoki to szybko poumiyrały (nazwisko Trawiński), to jedyn z Rogoszczokow to zrobiyt (nazwisko Rogowski) ${ }^{3}$. Trzeba zwrócić uwagę, że na wsi XVIII-wiecznej wytworzyła się tendencja odwrotna do tej, którą obserwuje się w tym czasie w mieście, gdzie derywaty z formantami $z$ podstawowym $-k$ - były rozbudowywane poprzez zastosowanie formalnych modeli z sufiksem -ski oraz -ewicz, -owicz. Dowodzi to popularności sufiksów z podstawowym - $k$ - w wiejskiej wspólnocie komunikacyjnej, zarówno w modelach słowotwórczych, według których derywowano nazwiska ze struktur semantycznych, jak i w modelach, które miały charakter wyłącznie formalny i służyły do derywowania nowych form nazwiskowych.

Popularność modeli formalnych w danej wspólnocie komunikacyjnej sprawdzić można już nie na poziomie systemu słowotwórczego, ale wyłącznie

3 Formy te zanotowałem we wsi Biechowo koło Wrześni w 1991 roku. Znane były tylko osobom z najstarszego pokolenia. 
na poziomie tekstowym, badając nazwiska koreferencyjne, czyli referujące tę samą osobę. Mówienie o popularności, a nie o produktywności ma uzasadnienie, jeśli weźmie się pod uwagę, że kształt nazwiska w konkretnej sytuacji komunikacyjnej uzależniony był nie tylko od możliwości systemowych, ale przede wszystkim od czynników zewnętrznych, związanych z wartościowaniem określonych modeli nazwiskotwórczych. W badanych tekstach zrekonstruować można trzy sytuacje, związane z funkcjonowaniem różnych formalnie nazwisk odnoszących się do jednaj osoby. Najliczniejszą grupę stanowią derywaty wchodzące w relację: derywat nazwiskowy podstawowy - derywat rozbudowany sufiksalnie:

a) sufiks $-a k$

Czarny-Czerniak:

Jacobo Czarny et Sophia de V. Sokołowo. (1763)

Jacobus Czerniak de V. Sokołowo. (1758)

Joanne Czarny et Catharina de V. Psary. (1757)

Joanne Czerniak et Catharina de V. Psary. (1763)

Klimek-Klimczak

Valentino Klimek et Marianna de V. Sokołowo. (1760)

Valentino Klimaczak et Marianna de V. Sokołowo. (1766)

Kosztur - Koszturak

Martinus Kosztur adolescens de eadem V. Słomowo.

(1744, 1746)

Martinus Koszturak adolescens de V. Słomowo. (1746)

Łuczak-Łuczaczyk

Luca Łuczak et Antonina de V Chociczka. (1766)

Luca Łuczaczyk et Antoninade V. Gutowo. (1762)

Paczesny-Pacześniak

Antonio Paczesny Semicmethone et Agnetede V. Sokołowo. (1758)

Antonio et agnete Paczesniakow de V. Sokołowo. (1761) 
Próchnicki-Próchniczczak

Alberto Prochnicki et Reina de V. Chociczka. (1766)

Albertum Pruchniczczak Pruchniczczak de V. Chociczka. (1753)

Siwy-Siwiak

Joannis et Reginae Siwych de V. Psary. $(1727,1732)$

Joannis et Reginae Siwiakow de V. Psary. (1730)

Wielgosz - Wielgoszczak

Ignatio Wielgosz Semicmethone et Regina de V Chociczka.

(1741)

Ignatio Wielgoszczak et Regina Semicmethonibus de V

Chociczka. (1753)

Witczak - Witoszczak

Nicolaus Witczak [Chociczka]. (1704)

Nicolaus Witoszczak [de V. Chociczka]. (1702)

Witek-Witczak

Jacobi et Catharinae Witkow de V. Chociczka. (1704)

Jacobi et Catharinae Witczakow de Chociczka. (1700)

b) sufiks -ek

Gasior-Gąsiorek

Martinus Gąsior de V. Chociczka. (1762)

Martino Gąsiorek et Marianna de V. Chociczka. (1758)

c) sufiks $-i k /-y k$

Chatas /Chatasik

Alberto Chałas et Marianna CL Semicmethonibus

de V. Chociczka. (1743)

Alberti Chałasik et Mariannae de V. Chociczka. (1738)

Śmigacz - Śmigaczyk

Vincentio Smigacz et Marianna de V. Słomowo. (1756)

Vincentio Smigaczyk et Marianna de V. Słomowo. (1753) 
d) sufiks $-k a$

Gomółka-Gomółczak

Alberti et Ursulae Gomołczakow de V. Psary. (1725)

Alberti et Ursulae Gomołkow Cmethonum de V. Psary. (1732)

Joannis et Gertrudis Gomołkow de V. Psary. (1729)

Joannis et Gertrudis Gomołczakow Cmethonum de V. Psary.

(1731)

Joannes Gomołczak Semicmethone et Regina de V. Psary. (1755)

Joannes Gomołka et Reina de V. Psary. (1763)

Kupidura - Kupidurka

Gregorius Kupidurka de V. Słomowo. (1730)

Gregory et Hedvigis Kupidurkow Cmethonum de V. Słomowo.

$(1728,1730)$

Moneta-Monetka

Joannis et Annae Monetow de V. Słomowo.(1717)

Joannis et Annae Monetow Cmethomum de V. Słomowo. (1727)

Joannis et Annae Monetkow de V. Słomowo. (1722)

Rochum Moneta de Bierzglinko. (1756)

Rochus Monetka adolescens vulgo Parobek de eadem

V. Bierzglinko. (1752)

Szykuła-Szykutka

Jacobus Szykuła de V Chociczka. (1752)

Jacobus Szykułka de V. Chocicza. (1757)

Tabaka - Tabaczka

Alberto Tabaka et Magdalene de V. Sokołowo. (1750)

Adalberto Tabaczka Semicmethone et Magdalena de

V. Sokołowo. (1750, 1754)

Poświadczone w przytoczonych kontekstach nazwiska najczęściej rozbudowywane były przez formant -ak. Występuje on w zestawieniach, które kontynuują wyraźnie relacje motywacyjne obecne także na gruncie apelatywnym i stamtąd przejęte na poziom proprialny, np. Czarny - Czerniak. W większości 
są to już jednak relacje powstałe na gruncie nazwiskowym, np. Kosztur-Koszturak (na poziomie apelatywnym: kosztur - koszturek). Warto zauważyć, że formant ten w jednym przypadku został wykorzystany do rozszerzenia formacji nazwiskowej utworzonej według modelu słowotwórczego z formantem -ski: Próchnicki - Próchniczczak. Dość często występuje w badanych tekstach również formant $-k a$. Jego obecność w derywatach warunkowana jest wyłącznie zasadami łączliwości formantów, przejętymi z derywatów apelatywnych. We wszystkich zanotowanych w zapiskach wrzesińskich przypadkach formant ten łączy się tylko z podstawami rodzaju żeńskiego.

Drugi z wymienionych wyżej typów tworzą relacje trójelementowe, złożone z nazwiska podstawowego oraz dwóch form nazwiska pochodnego. Analogicznie jak wyżej są to relacje między formami nazwisk koreferencyjnych. W badanych tekstach zostały poświadczone dwa takie układy:

Chałas - Chałasiak-Chałasik

Stanislao Chałas et Hedviga de V. Chociczka. (1756)

Stanislao Chałasiak de V. Chocicza. (1753)

Stanislaus Chałasik de V. Chocicza. (1752)

Nowak - Nowaczak - Nowaczyk

Alberto Nowak de V. Psary. $(1760,1762)$

Alberti Nowaczak de V. Psary. (1748)

Albertus Nowaczyk Famulus de V. Psary. (1762)

Również dwukrotnie poświadczona została sytuacja: nazwisko derywowane - nazwisko derywowane. Znamienne jest to, że w badanych zestawieniach występują wyłącznie relacje pionowe, tworzone przez derywaty jednego tylko rodzaju: $\mathrm{z}$ formantami $-a k,-i k /-y k$, -ek. Pary te nie tworzą relacji o charakterze motywacyjnym, trudno bowiem wskazać kierunek motywacji. Formanty w tych nazwiskach mogły się dowolnie wymieniać.

Manaszek-Manesik

Simonis et Reginae Manaszkow de V. Gutowo. (1732)

Simonis et Reginae Manesikow Inquilinorum de Gutowo. (1734)

Szykulak-Szykułka

Martino Szykulak et Marianna de V. Chocicza. (1753)

Martino Szykułka et Marianna de V. Chocica. (1757) 
W dwóch ostatnich grupach, analogicznie jak w pierwszej, największą aktywnością słowotwórczą charakteryzuje się formant $-a k$.

Skulina [1989: 199], podsumowując część artykułu poświęconą formantom z podstawowym - $k$-, pisze: ,[...] niektóre z formacji patronimicznych mogły być w rzeczywistości wariantami, a więc i powtórzeniami nazw podstawowych, używanymi fakultatywnie i tylko okresowo (zwykle w młodości ich nosicieli)". Prowadzone wyżej analizy funkcjonowania modeli słowotwórczych sądu tego nie potwierdzają. Materiał poświadcza wprawdzie sytuacje, kiedy nazwisko z formantem poprzedza w czasie nazwisko podstawowe, np. Czerniak (1758) - Czarny (1763), ale dokumentuje też inne możliwości rozkładu formantów w czasie w tym samym nazwisku. I tak nazwisko derywowane występuje później niż podstawowe, np. Klimek (1760) - Klimczak (1766), lub nazwisko podstawowe pojawia się na przemian z nazwiskiem derywowanym, np. Siwy (1727) - Siwak (1730) - Siwy (1732). Poświadczone w konkretnych aktach komunikacyjnych derywaty tworzące określone związki motywacyjne są warunkowane nie tyle semantycznie, ile sposobem funkcjonowania w danej wspólnocie komunikacyjnej formalnych modeli słowotwórczych, które umożliwiały (a zezwalał na to system i ówczesny uzus słowotwórczy w nazwiskach) tworzenie dowolnej formy nazwiska w danym akcie komunikacyjnym. Kwestią przypadku jest, która z tych form się ostatecznie utrwaliła.

\section{Derywaty z formantem -ski (i pochodnymi)}

Formant -ski, bezwyjątkowy w notowanych w badanych dokumentach nazwiskach szlacheckich i tworzący najliczniejszą grupę nazwisk mieszkańców Wrześni, wykazuje stosunkowo niedużą produktywność w nazwiskach mieszkańców wsi. Jak pokazuje tabela 1., poświadczony jest w 52 derywatach nazwiskowych.

Od połowy XVI wieku w systemie słowotwórczym nazwisk polskich wytworzyły się formalne modele słowotwórcze z tym formantem, których charakterystyczną cechą jest to, że tworzą nowe jednostki nazwiskowe od nazwisk już istniejących. Opis słowotwórczy wymaga zatem wyodrębnienia nazwisk delokatywnych, derywowanych ze struktury semantycznej oraz derywatów powstałych z użyciem formalnych słowotwórczych modeli nazwiskowych. W wielu przypadkach trudno jednak jednoznacznie orzec, czy podstawę stanowi nazwa miejscowa, a tym samym nazwisko powstało poprzez derywację ze struktury semantycznej, czy nazwisko, które równe jest podstawie nazwy lokatywnej (Bartoszewski: Bartoszewo > Bartoszew-ski czy Bartosz > Bartosz-ewski?). W takim przypadku konieczne są decyzje arbitralne. Jeśli dla danego derywatu można znaleźć jako podstawę słowotwórczą nazwę miejscową, traktuję go jako odmiej- 
scowy. ${ }^{4} \mathrm{~W}$ badanych tekstach zanotowano ogólem 52 derywaty z omawianym formantem, z czego 32 to nazwiska motywowane przez nazwy lokatywne, a 20 to derywaty utworzone $\mathrm{z}$ udziałem formalnych modeli słowotwórczych.

Do pierwszej grupy należą: Brzeziński < Brzeziny, Chęciński < Checiny, Chojnoski $<$ Chojny/Chojno, Dankoski $<$ Danków, Dziedzicki $<$ Dziedzice, Dzierzbinski $<$ Dzieżbin, Golczynski $<$ Gulcz, Jagodzki $<$ Jagodno, Jankoski $<$ Jankow/Jankowo, Jarocki < Jaroty, Jasinski < Jasin, Krąkowski $<$ Krąków, Krzywański $<$ Krzywań, Nadworski $<$ Nadwory, Obiezierski $<$ Objezierze, Orłoski $<$ Orlowo, Próchnicki $<$ Próchnik, Przedziecki $<$ Przezdzięka, Rakowski $<$ Raków, Różycki < Rózyce, Rutkowska $<$ Rudki, Sosnowski < Sosnowo, Sowinski $<$ Sowin, Szymański $<$ Szymany, Topoleski $<$ Topolewo, Wesołowski $<$ Wesołów, Wojciechowski $<$ Wojciechów, Wolski $<$ Wola, Wroński $<$ Wronal Wrony, Wróblewski $<$ Wróblewo, Zagórecki $<$ Zagórki.

Derywaty motywowane przez nazwisko to: Bujeski < Buja/Bujo, Grubski $<$ Gruby, Gruchocki < Gruchot, Jabczyński < Jablko, Jabłoński $<$ Jabłoń, Kamecki $<$ Kamka, Kostrzeski $<$ Kostrzewa, Krzywoski $<$ Krzywosz, Maśliński $<$ Masto, Naskręcki < Naskret, Nawrocki $<$ Nawrot, Ochocki $<$ Ochota, Podkówczyński < Podkówka, Poturalski < Poturała, Przybylski $<$ Przybyt, Sieczyński $<$ Sieczka, Sikorski $<$ Sikora, Skowroński $<$ Skowron, Stachulski $<$ Stachuła, Szulczewski < Schulz, Tycewski < Tyc, Warkoczeski < Warkocz.

Większość derywatów nazwiskowych utworzona została za pomocą sufiksu -ski. Sufiksy złożone, pochodne od niego, są bardzo rzadkie. Szczegółowy rozkład formantów w poszczególnych grupach derywatów przedstawia tabela 3. Ze względu na pojedyncze poświadczenia sufiksów złożonych rezygnuję z obliczeń procentowych.

Tabela 3. Derywaty z sufiksem -ski (i pochodnymi)

\begin{tabular}{|l|c|c|}
\hline \multicolumn{1}{|c|}{ Formant } & Derywaty odmiejscowe & Derywaty odosobowe \\
\hline- ski & 30 & 16 \\
\hline -iński/-yński & 1 & 2 \\
\hline -ewski & 0 & 2 \\
\hline -owski & 1 & 0 \\
\hline
\end{tabular}

4 W literaturze przedmiotu przyjmuje się też inne rozwiązanie. Derywaty, dla których można znaleźć podwójną motywację, zgodnie z zasadami słowotwórstwa apelatywnego traktuje się jako wielomotywacyjne [zob. np. Jaracz 2001]. 
Tabela pokazuje bardzo małą produktywność na badanym obszarze formalnych modeli słowotwórczych $\mathrm{z}$ omawianym formantem. To dodatkowo thumaczy dużą liczebność derywatów z formantami opartymi na sufiksach z podstawowym $-k$ - Przez całe stulecie tylko jeden raz poświadczony został udział formalnego modelu z omawianym sufiksem w tworzeniu nazwisk koreferencyjnych:

$$
\text { Przybyt-Przybylski }
$$

Michaele Przybeł et Clarae de V. Słomowo. (1763, 1765)

Clara Przybylska de V. Słomowo (1759)

Dwukrotnie derywat nazwiskowy z formantem -ski został rozbudowany przez dodanie formantu - $a k$. Raz działanie takie miało motywację semantyczną (zob. wyżej Chojnacki-Chojnaczczak), raz było to przekształcenie formalne (zob. Próchnicki-Próchniczczak).

\section{Derywaty $\mathrm{z}$ formantem -ewicz, -owicz}

W badanych dokumentach zanotowano tylko 7 derywatów z tymi formantami. Wszystkie zostały poświadczone dopiero w 2. połowie XVIII wieku: Jakubowicz, Jurkiewicz, Malewicz, Miśkiewicz, Perkowicz, Różewicz, Ziółkowicz.

$* * *$

Prowadzone badania pokazują, że przez cały XVIII wiek dominują w procesie tworzenia derywatów nazwiskowych modele słowotwórcze z sufiksami z podstawowym $-k$ - Taki stan nazwiskowego systemu słowotwórczego potwierdza wcześniejsze ustalenia Bubaka [1986], który te sufiksy uznał za wyróżniki nazwisk chłopskich. Na wsi podwrzesińskiej modele słowotwórcze z tymi formantami stanowią podstawę derywowania większości nazwisk. W badanych tekstach zaskakuje bardzo duża produktywność formantu -ak. Poświadczany jest on zarówno jako formant podstawowy w formalnych modelach słowotwórczych, jak i jako wykładnik relacji patronimicznej. Notowany jest on także w innych opracowaniach, ale nigdzie nie plasuje się na pierwszym miejscu. Jako przykład warto przytoczyć dane z północno-wschodnich terenów Rzeczpospolitej, gdzie, jak wynika z badań Leonardy Dacewicz [2014: 109], wśród tworzących nazwiska chłopskie najpopularniejszy był formant -uk, -czuk. Warto zauważyć jednak tendencję o charakterze bardziej ogólnym: na obszarze Rzeczpospolitej dominującymi typami słowotwórczymi, według których derywowano nazwiska chłopskie, były typy z formantam z podstawowym $-k$ - Inaczej wygląda tylko frekwencja poszczególnych formantów 
w procesie derywowania nazwisk. Potwierdza to wcześniejszą tezę, stawianą przez Bubaka [1986].

Marginalne znaczenie (tylko przy tworzeniu derywatów formalnych) miał sufiks -ski i sufiksy pochodne. Przez cały wiek powstało z ich udziałem tylko 20 formacji. Nie można tu zaliczyć tych, które utworzone zostały od nazw miejscowych. Derywowanie aktualnych nazwisk na -ski z podstaw semantycznych wygasło już w XVII wieku. Poświadczone w tekstach derywaty to tylko leksykalne dziedzictwo z przeszłości.

Stan obserwowany w dokumentach pozwala założyć, że w ogóle nie występowały na terenie wsi podwrzesińskich modele słowotwórcze $\mathrm{z}$ formantami -ewicz i -owicz. Poświadczone nazwiska, zanotowane między 1753 a 1760 rokiem, zostały prawdopodobnie przeniesione z zewnątrz. Było ich zdecydowanie za mało, by wytworzyć produktywny model słowotwórczy.

\section{Bibliografia}

Bubak Józef (1986), Proces ksztattowania się polskiego nazwiska mieszczańskiego i chtopskiego, Uniwersytet Jagielloński, Kraków.

Dacewicz Leonarda (2014), Historia nazwisk na kresach pótnocno-wschodnich Rzeczpospolitej (XVI-XVIII w.), Wydawnictwo Uniwersytetu w Białymstoku, Białystok.

Jaracz Małgorzata (2001), Nazwiska mieszkańców Kalisza od XVI do XVIII wieku, Wydawnictwo Akademii Bydgoskiej im. Kazimierza Wielkiego, Bydgoszcz.

Kaleta Zofia (1991), Ewolucja nazwisk słowiańskich, PAN, Instytut Języka Polskiego, Kraków.

Klisiewicz Edward (1976), Omówienie w funkcji nazwiska w Księgach parafialnych wsi Rudawa k. Krakowa w XVI-XVIII w., „Rocznik Naukowo-Dydaktyczny WSP w Krakowie. Prace Językoznawcze III”, z. 8, s. 97-104.

Mączyński Maciej (2002), Sposoby identyfikacji osób w sądzie (na podstawie XVII-wiecznych ksiag grodzkich wsi Jadowniki), w: Rozmaitości językowe ofiarowane Prof. dr. hab. Januszowi Strutyńskiemu z okazji Jego jubileuszu, red. Mirosław Skarżyński, Marianna Szpiczakowska, Księgarnia Akademicka, Kraków, s. 195202.

Rudnicka-Fira Elżbieta (2004), Antroponimia Krakowa od XVI do XVIII wieku, Wydawnictwo Uniwersytetu Śląskiego, Kraków.

Sieradzki Andrzej, Sieradzka Beata (2003), Grupy nominalne odnoszace się do matżonków we wrzesińskich ksieggach chrztu z XVIII wieku, w: Metodologia badań onomastycznych, red. Maria Biolik, Towarzystwo Naukowe, Ośrodek Badań Naukowych im. Wojciecha Kętrzyńskiego, Olsztyn, s. 167-176. 
Sieradzki Andrzej (2010), Antroponim jako podstawa grupy nominalnej w poznańskich księgach złoczyńców z XVI wieku, w: Mnohotvárnost a specifičnost onomastiky, Ostrava, s. 424-430.

Sieradzki Andrzej (2011), Identyfikacja rodziców stanu chłopskiego we wrzesińskich księgach chrztu z lat 1700-1725, „Poznańskie Studia Polonistyczne, Seria Językoznawcza", t. 18, z. 1, s. 129-144.

Sieradzki Andrzej (2013), Poznańskie derywaty nazwiskowe XVI-XVIII wieku, Rys, Poznań.

Sieradzki Andrzej (w druku), Słowotwórstwo nazwisk mieszkańców Szamotuł z końca XVI wieku.

Skulina Tadeusz (1989) O ustalaniu się nazwisk mieszczańskich i chłopskich $w$ Wielkopolsce w XVII wieku, „Onomastica”, s. 183-208.

Andrzej Sieradzki

\section{Word Formation of Names of Rural Residents in the Baptismal Books of Września from the 18th Century}

The article studies name derivatives referring to rural population recorded in the eighteenth-century baptismal books of Września. The core of the study are 164 surnames formed by the addition of the suffixes -ski, -ewicz, -owicz as well as the basic $-k$-. The studies completed demonstrate that in the process of creation of names, over the entire 18th century, the most dominating were the word formation models with suffixes including the basic $-k$-. Within this category the suffix $-a k$ was the most active element. Of marginal importance (only in the creation of formal derivatives) was the suffix -ski and the derived suffixes. Only 20 formations were created with their use during the whole century. On the basis of the analysis of the documents, it can be assumed that in the rural area near Września there were no word-formative models with the formatives -ewicz and -owicz. The attested surnames (7), recorded between 1753 and 1760, must have been brought from other areas.

KEYwORDs: Września; surnames; word formation; word-formation models; jurors' books.

prof. dr hab. Andrzej Sieradzki - Zakład Lingwistyki Antropologicznej, Instytut Filologii Polskiej Uniwersytetu im. Adama Mickiewicza; zainteresowania naukowe: słowotwórstwo historyczne, leksykologia historyczna, onomastyka, w tym głównie antroponimia Wielkopolski. 